\title{
Research on the Influence of Offline Classroom Learning Participation on Undergraduates' Learning Effect Based on the Involvement Theory
}

\author{
Chuanyu Peng ${ }^{1, *}$ Yue Liu ${ }^{1}$
}

\author{
${ }^{1}$ School of Public Affairs and Law, Southwest Jiaotong University, Chengdu, Sichuan 610031, China \\ *Corresponding author. Email: 1337825734@qq.com
}

\begin{abstract}
Based on the involvement theory, the paper constructed the evaluation index of undergraduates' classroom learning participation from five dimensions: attendance rate, seriousness of attending class, note-taking, class discussion, and teacher-student interaction. Through 182 sample data, the influence of college students' classroom participation on the overall learning effect of the course was explored. The results of the study found that there is a significant positive correlation between the undergraduates' classroom learning participation and the overall learning effect. On the basis of empirical research, the paper gave relevant countermeasures and suggestions.
\end{abstract}

Keywords: Involvement theory, Classroom learning participation, Overall learning effect.

\section{INTRODUCTION}

The Ministry of Education proposed at the National Undergraduate Education Work Conference in the New Era on June 21, 2018 that it is necessary to adhere to the principle of "Based on undergraduate education". It is advocated that undergraduate education return to common sense, and education should be centered on students studying hard, and guide students to seek truth, learn and practice true skills. In addition, it is necessary to increase the burden on college students reasonably, increase their academic challenges, stimulate their motivation and professional aspirations, change the situation of easy graduation, and truly embody the construction of connotation and the improvement of quality in each student's study effect. Universities in China have been working hard to improve the quality of undergraduate education, learning from the advanced experience of European and American universities, constantly improving undergraduate education from the system level, technical scope and faculty, and using active improvement to solve the quality problems of undergraduate education for college students. These methods and measures have played a positive role, and students' academic quality, test scores, foreign language ability and other aspects have been significantly improved. But at the same time, the effectiveness of college students' classroom learning is closely related to their own input and control in the learning process (Zichuan MIi et al, 2018). The internal motivation of students' learning is an important factor in improving academic performance. As an important part of college students' learning investment, classroom participation plays an important role in improving the overall learning effect of students.

\section{LITERATURE REVIEW}

The classroom learning participation is an important part of undergraduates' learning in school. Some scholars pointed out that there is a positive correlation between classroom learning participation and academic performance (Finn, 2002), especially in the learning of English courses (Zhisong Li, Pengli Deng, 2016). The research of Ye Zhang and Dajun Zhou (2004) also found that active classroom participation activities, whether verbal or non-verbal, have a positive role in promoting English learning, while passive participation will not be conducive to English learning. However, these studies only paid attention to the influence of classroom participation on 
academic performance, and did not pay attention to the influence of classroom participation on the overall learning effect of students' personal ability and comprehensive quality. Astin (1984) put forward the theory of involvement in the 1980s, which believes that: involvement means the input of physical and psychological energy; the change of involvement is a continuum, and the energy invested in activities by different students varies with time and goals. Involvement has both quantitative and qualitative elements; the student's learning and development are proportional to the quality and quantity of his involvement in learning activities; the effectiveness of any educational practice is directly related to its ability to increase student involvement. According to this theory, classroom learning participation not only affects students' academic performance, but also affects students' psychological development. On the basis of "involvement theory", Qi Zeng (2001) believes that participation can promote students' grasp of knowledge and improve students' academic performance. At the same time, participation also has non-cognitive functions. Participation can increase students' interest in learning, cultivate students' positive attitudes toward learning, enhance students' perseverance in the face of difficulties in learning and other willful qualities, enhance students' sense of self-efficacy, and improve students' satisfaction with learning activities, etc. (Qi Zeng,2001). Therefore, the learning effect brought by classroom participation should be a multi-faceted overall improvement for students.

In view of this, on the basis of the involvement theory, the author constructs an evaluation index of the degree of undergraduates' classroom learning participation composed of five dimensions: attendance rate, seriousness of attending class, note-taking, classroom discussion, and teacherstudent interaction, and adopts empirical research methods to explore the relationship between undergraduates' classroom learning participation and their overall learning effects.

\section{RESEARCH DESIGN}

\subsection{Student Classroom Participation Behavior}

Student participation is a state variable that reflects the physical and psychological energy invested by students in activities related to their studies (Carmody et al, 1984). Students' classroom participation is a way for them to gain knowledge and improve themselves. Yishuang Hao (2007) pointed out several characteristics of student classroom participation in his research: Firstly, the main body of participating behaviors is mostly student groups, and there are very few individual students participating in classroom activities. Secondly, most of the students' participation is passive obedience and lack of initiative. In observation, it is found that the student's verbal interaction directed to the teacher is to answer the question according to the teacher's request, and the student's participation is mainly "response" behavior. Thirdly, the objects of interaction are mostly the interaction between teachers and students, and there is almost no communication between students. According to the definition of participation and three characteristics of student classroom participation, this article divides classroom participation into five types of behaviors: participation (attendance), personal input (mainly in listening to lectures, taking notes), interaction between students (group discussion), and interaction between students and teachers.

\subsection{Overall Learning Effect}

Cuili Song (2011) observed the relationship between students' classroom participation and selfconcept, and concluded that there is a significant positive correlation between them. It can be seen that individuals not only gain knowledge through classroom participation, but also develop various personal abilities such as cognitive ability and communication ability. Piaget (1981) emphasized in his generative epistemology that the internal intellectual process originated from activities. The development is the process in which individuals continue to assimilate and adapt to the environment in their activities, and internalize external activities into internal psychological structures. Individual participation in activities is a prerequisite for internalization of external activities. Therefore, without individual participation in activities, there will be no individual growth and development. This also shows that participation is a key basis for individual development and personal ability improvement. The individual interacts with the surrounding environment during the process of participation, internalizes, constructs new ideas and develops. This is the learning effect obtained through participation. Furthermore, according to the "involvement theory", the degree of this learning effect is directly related to the quality and quantity of involvement and the ability of students to be involved. This article uses the lessons learned, 
learning initiative, thinking ability, problem-solving ability, social ability, and cooperation ability to measure the overall learning effect of students.

\subsection{Questionnaire Sampling}

In order to ensure the reliability and validity of the measurement tool, this study refers to the scale used in the existing literature and adopts a measurement scale with a standard reliability and validity. The questionnaire is measured using a tenlevel evaluation scale, and the evaluation is scored on a scale of 1-10.

The study selected freshmen and sophomores from a university in Chengdu as the research objects. The random sampling method was adopted to conduct group sampling according to the dormitory buildings of the students. A total of 200 dormitories were sampled, and the students with the No. 1 bed in each dormitory were selected to fill in the questionnaire. A total of 37 questionnaires were distributed to freshman boys and 60 questionnaires to freshmen girls; 43 questionnaires were distributed to sophomore boys and 63 questionnaires were distributed to sophomore girls. A total of 200 questionnaires were returned. After the questionnaire was collected, the validity of the questionnaire was evaluated according to 4 criteria: filling time; filling in the question item completeness; filling regularity; obviously

Table 1. Measuring the average scores of items in class learning participation measuring the consistency of the answers to two questions with the same indicator. As long as one of the above criteria is inconsistent with the questionnaire answering situation, it is considered invalid and removed. A total of 18 questionnaires were removed and 182 valid questionnaires were obtained. The effective rate of the questionnaire was $91.0 \%$.

\section{DATA ANALYSIS}

\subsection{Descriptive Analysis}

In this study, five indicators including attendance rate, seriousness of attending class, note-taking, group discussion, and teacher-student interaction were used to measure class participation. A total of 8 items were set. Among them, each has 1 item to measure attendance rate and the degree of seriousness of attending a class, and 2 items each measure note-taking, group discussion, and teacher-student interaction (Mei Qing, 2016). In addition, Question 9 measures the overall self-evaluation of the students participating in the survey on their own classroom participation, with an average of 6.2 , which is similar to the average classroom participation of 6.1142 measured by the first 8 sub-index items (see "Table $1 ")$.

\begin{tabular}{lllll}
\hline \multirow{2}{*}{ Variable } & \multicolumn{1}{c}{ Item } & Mean & $\begin{array}{c}\text { Standard } \\
\text { error }\end{array}$ & $\begin{array}{c}\text { Number of } \\
\text { cases }\end{array}$ \\
& Q1 Attendance rate & 9.29 & 1.365 & 182 \\
& Q2 Seriousness of attending class & 6.71 & 1.779 & 182 \\
Class & Q3 Note-taking frequency & 5.93 & 2.649 & 182 \\
participation & Q4 How many notes do students take & 5.79 & 2.147 & 182 \\
& Q5 Frequency of participating in group discussions & 7.24 & 2.491 & 182 \\
& Q6 Activeness of speaking in the group & 6.41 & 2.227 & 182 \\
& Q7 Frequency of proactively answering teacher's questions & 4.2 & 2.579 & 182 \\
& Q8 Frequency of asking the teacher & 3.26 & 2.359 & 182 \\
& Q9 Self-evaluation of classroom participation & 6.2 & 2.009 & 182 \\
\hline
\end{tabular}

It can be seen from the "Table 1 " that the average attendance score of the students is 9.29, which means that most people have a score of 10 ; the average scores for measuring students' seriousness in class, taking notes, and group discussions are all high. Between 5-7 points, while measuring the teacher-student interaction questions, the average score of the students is relatively low, the average score of "actively answering teacher questions" is only 4.2, and the average score of "questing teachers" is only 3.26.
There are a total of 8 items in the measurement of learning effect, which are used to measure the students' learning autonomy, thinking ability, problem-solving ability, social ability, cooperation ability, the degree of improvement in the willingness to learn in the course of study, the degree of harvest and the degree of achievement of expected goals. The average score for each question is around 6 points (See "Table 2"). 
Table 2. Measuring the average scores of items in learning effect

\begin{tabular}{|c|c|c|c|c|}
\hline Variable & Item & Mean & $\begin{array}{c}\text { Standard } \\
\text { error }\end{array}$ & $\begin{array}{l}\text { Number } \\
\text { of cases }\end{array}$ \\
\hline \multirow{8}{*}{ Learning effect } & Q10 Self-evaluation of classroom harvest & 6.42 & 1.907 & 182 \\
\hline & Q11 This course has improved my learning initiative & 5.91 & 2.206 & 182 \\
\hline & Q12 This course has improved my thinking ability & 6.37 & 1.973 & 182 \\
\hline & Q13 This course has improved my problem-solving ability & 6.2 & 1.864 & 182 \\
\hline & Q14 This course has improved my social skills & 5.47 & 2.281 & 182 \\
\hline & Q15 This course has improved my ability to cooperate & 5.92 & 2.265 & 182 \\
\hline & Q16 I reached my expected goal for this course & 6.18 & 2.071 & 182 \\
\hline & Q17 I am willing to learn more about the content of this course & 6.62 & 2.067 & 182 \\
\hline
\end{tabular}

\subsection{Reliability and Validity Test}

SPSS 24.0 was used to test the reliability of the questionnaire measuring classroom participation and learning effects. The Cronbach $\alpha$ coefficients of the classroom participation and learning effect scales are both greater than 0.8 , indicating that the scales have a high degree of internal consistency and good measurement reliability. KMO test and Bartlett sphericity test are used to test the validity of classroom participation and learning effects. The KMO value of classroom participation is 0.771 (greater than 0.5), the significance of Bartlett's sphericity test is 0.000 (less than 0.001 ); the KMO value of overall learning effect is 0.897 greater than 0.5 , and the significance of Bartlett's sphericity test is 0.000 and less than 0.001 . This shows that the measurement questionnaire has high validity.

\subsection{Correlation Analysis and Regression Analysis}

The researchers use SPSS 24.0 to test the correlation between classroom participation and overall learning effect. The data shows that there is a significant positive correlation between classroom participation and the overall learning effect, with a correlation coefficient of 0.744 . The regression equation is further used to test the relationship between classroom participation and overall learning effect. The data results show that learning effect $=0.744 \times$ class participation $+0.944, \mathrm{p}<0.001$. (See "Table 3").

Table 3. Regression analysis of classroom participation and learning effect

\begin{tabular}{|c|c|c|c|c|c|c|c|}
\hline \multicolumn{5}{|c|}{ Unstandardized coefficient } & \multicolumn{3}{|c|}{ Standardized coefficient } \\
\hline $\begin{array}{l}\text { Model } \\
\text { (Constant) }\end{array}$ & $\mathrm{R}$ & $\mathrm{R} 2$ & $\begin{array}{l}\mathrm{B} \\
0.944\end{array}$ & $\begin{array}{l}\text { Standard error } \\
0.357\end{array}$ & Beta & $\begin{array}{l}\mathrm{t} \\
2.641\end{array}$ & $\begin{array}{l}\text { Significance } \\
0.009\end{array}$ \\
\hline $\begin{array}{l}\text { Classroom } \\
\text { participation }\end{array}$ & $0.744^{\star}$ & 0.554 & 0.851 & 0.057 & 0.744 & 14.958 & 0.000 \\
\hline
\end{tabular}

\section{CONCLUSION}

The main conclusions of this research are as follows: The classroom participation of college students has a significant positive correlation with the overall learning effect. The degree of classroom participation of college students will affect the overall learning effect of college students. Based on the research conclusions, the following countermeasures are proposed:

First of all, classroom teachers should actively pay attention to students' classroom participation. At the university level, students' classroom participation has a certain degree of freedom and randomness. If the requirements of the classroom teacher are not clear, the students' participation in the classroom will be much weaker in the higher learning stage. Therefore, from the perspective of improving the overall learning effect of college students, teachers should actively pay attention to the level of student participation in the classroom while paying attention to the content of their own lectures.

Secondly, classroom teachers need to fully consider the various modes of classroom participation. In addition to cognitive listening and note-taking, group discussions, teacher-student interactions, student questions, etc. are all to promote students' enthusiasm for learning and improve the degree of students' involvement in courses. Diversified participation is more conducive to the improvement of the overall learning effect. Class teachers can try to improve their own teaching design. For example, adjust the 
course objectives and teaching methods, increase classroom discussion links, optimize the ratio of teacher speech and student classroom speech, carry out more group activities and pairing activities, increase questions, and guide students to participate more in classroom activities.

At the same time, in the course score design, the teacher can increase the scoring and proportion of classroom participation, and encourage more students to actively participate in the course by means of score incentives, so that students who actively participate in the classroom can obtain higher scores and improve the overall learning effect.

Finally, for college students, they need to increase their knowledge of learning in a variety of ways. Undergraduates' general knowledge of learning comes from external reasons (parental requirements, social needs, etc.), and there is still a lack of exploration of their own internal needs and learning motivation. Therefore, to improve college students' classroom participation, they need to deepen their own understanding of learning, recognize the significance of curriculum learning participation in improving their overall learning effect, take the initiative to learn, actively participate in the classroom, and actively use the opportunity of classroom participation to improve their own comprehensive abilities such as thinking ability, social ability, learning ability and teamwork ability.

\section{AUTHORS' CONTRIBUTIONS}

This paper is completed by Chuanyu Peng and Yue Liu. Chuanyu Peng is responsible for the research ideas and frame structure design of the paper. Yue Liu is responsible for literature collection, data statistics and analysis, paper writing and revision.

\section{ACKNOWLEDGMENTS}

This study was supported by the postgraduate teaching reform project of Southwest Jiaotong University (YJG4-2020-TZ07-2) and the undergraduate teaching reform project of Southwest Jiaotong University (20201049-01)

\section{REFERENCES}

[1] Zichuan Mi, Yi Li, Yanan Guo. The influence of process learning input on college students' academic performance-a comparison based on
NSSE measurement [J]. Higher Education Theory and Efficient Management, 2018 (21): 6-14.

[2] Finn. Participation and withdraw among fourth-grade pupils. American Educational Research Journal, 2002(29):141 -162.

[3] Zhisong Li, Pengli Deng. An Empirical Study on the Relationship between College Students' English Class Performance and Academic Performance $[\mathrm{J}]$. Journal of Huaibei Normal University (Philosophy and Social Sciences Edition), 2016, 37(05): 150-154.

[4] Ye Zhang, Dajun Zhou. Research on the Model of College English Students' Classroom Participation [J]. Foreign Languages World, 2004(06): 28-33.

[5] Astin, A .W. (1984).Student involvement: A developmental theory for higher education Journal of College Student Personnel, 25, 297-308.

[6] Qi Zeng. Student participation and its development value [J]. Subject Education, 2001(01): 4-7.

[7] Carmody, D.P. Kundel, H.L, Toto, L .C.Comparison scans while reading chest image: Taught, but not practiced .Investigative Radiology, 1984; 19:462-466.

[8] Yishuang Hao. Analysis of college students' classroom participation behavior [J]. Research in Higher Engineering Education, 2007(06):131-134.

[9] Cuili Song. Study on the relationship between primary school students' classroom participation, self-concept and academic performance [D]. Henan Normal University, 2011: 41-50.

[10] Piaget, translated by Wang Xiantian and others. Principles of Epistemology [M]. Beijing: The Commercial Press, 1981.

[11] Mei Qing. Empirical Test on the Construction of College English Effective Classroom Environment and Evaluation Scale $[\mathrm{J}]$. Educational Research, 2016, 37(04): 105-111. 